\title{
ERRATUM
}

A. Gouliaris · P. Kaklamanis · P. Papadakis

D. Kranias · D. Sambatziotis

\section{Sweet's syndrome with arthritis and vasculitis}

Published online: 6 April 2004

(C) Clinical Rheumatology 2004

\section{Clin Rheumatol (2003) 22:244-247}

In this contribution, the first initial of the first author was incorrectly rendered. The name and initial of the first author should read: A. Gouliaris.

The online version of the original article can be found at http:// dx.doi.org/10.1007/s10067-003-0692-7

A. Gouliaris · P. Papadakis · D. Kranias · D. Sambatziotis Athens Medical Center,

401 General Military Hospital,

Athens, Greece

P. Kaklamanis $(\bowtie)$

Athens Medical Center,

61 Ipsilantou Street,

11521 Athens, Greece

E-mail: virginia@hol.gr

Tel.: $(++30) 0107222067$

Fax: $(++30) 0107225962$ 